\title{
Quasi-Geostrophic Energetics Based on a Transformed Eulerian Equation with Application to Wave-Zonal Flow Interaction Problems
}

\author{
By Hiroshi Kanzawa \\ National Institute of Polar Research, 1-9-10 Kaga, Itabashi-ku, Tokyo 173, Japan \\ (Manuscript received 16 May 1983, in revised form 11 December 1983)
}

\begin{abstract}
On the basis of the transformed Eulerian-mean equation which includes Eliassen-Palm flux divergence or quasi-geostrophic potential vorticity transport for large-scale extratropical motions, a transformed energy conversion equation is derived for further understanding of the wave-zonal flow interaction. The transformed mean energy conversion equation is readily derived from the transformed mean equation. In order to obtain the transformed eddy energy conversion equation consistent with the transformed mean energy conversion equation, an attempt is made to transform the eddy equation, and the transformed energy conversion equation is constructed for both mean motion and eddy motion. It is shown that there is no conversion between the mean available potential energy and the eddy available potential energy formally in the transformed energetics.

The transformed energy conversion equation is applied to some theoretical problems such as Eady's baroclinic instability, upward propagating stationary planetary wave incident on a critical level and upward propagating planetary wave packet. For Eady's problem, the transformed energetics explicitly describes the significance of the existence of horizontal boundaries which is known to be essential to baroclinic instability. The behavior of energy conversion is simpler in the transformed energetics than in the ordinary energetics for the critical level problem and the wave packet problem since the transformed energy conversion equation does not include originally the term irrelevant to the net influence on the budget of energy in the result.

The new form based on the transformed equation is useful to understand the circumstances that the wave-mean flow interactions occur although there are some limitations in the energetics itself.
\end{abstract}

\section{Introduction}

The transformed Eulerian-mean equation for primitive equation system was first presented by Andrews and McIntyre (1976). The equation includes the Eliassen-Palm (E-P) flux divergence term which embodies the forcing of the mean zonal flow by the waves: the E-P flux represents momentum flux by the waves. In the quasigeostrophic approximation, the E-P flux divergence is identical to the meridional flux of quasigeostrophic potential vorticity which is a conservative quantity. The nature of the transformed Eulerian-mean equation and that of E-P flux for quasi-geostrophic motion were discussed, for example, by Sato (1980), Edmon et al. (1980), Palmer (1981) and Kanzawa (1982) in applica- tion to observational data.

In Section 3 I derive the transformed energy conversion equation for quasi-geostrophic motions which explicitly includes the E-P flux divergence or quasi-geostrophic potential vorticity transport. The transformed mean energy conversion equation is readily derived from the well-known transformed Eulerian-mean equation. In order to obtain the transformed eddy energy conversion equation consistent with the transformed mean energy conversion equation, it is necessary to transform the eddy equation. I present a transformation in Section 2.2. Terms of wave-wave interaction in the eddy equation and diabatic heating/cooling turn out to be irrelevant to the differences between the ordinary energetics first presented by Lorenz (1955) and 
the transformed energetics and do not appear in the problems to which the obtained energy equation is applied in the present study. Therefore they are not considered in the present study.

The two forms of energetics are compared in Sections 4,5 and 6 by applying to the three concrete problems in which wave-mean flow interaction occurs. The problem of Eady's baroclinic instability is taken up as an example in which the boundary flux at the horizontal rigid surfaces is the point at issue. The problem of upward propagating planetary wave incident on a critical level is mainly concerned with the energy conversion between the mean potential energy and the mean kinetic energy which comes from the mean meridional circulation induced by the wave incident on a critical level. The problem of upward propagating planetary wave packet is mainly concerned with the energy conversion of eddy energy by the wave transience. The mean meridional circulation induced by Eady's baroclinic waves has been theoretically obtained by Uryu (1979). The critical level problem has been treated by Matsuno and $\mathrm{Na}$ kamura (1979) and the wave packet problem by Uryu (1974) in terms of the wave momentum. I will use their solutions in order to calculate the energy conversions.

In all the above three problems the fluid is bounded by vertical rigid walls in the lateral direction. Therefore the energy flux at the lateral boundaries is easily found to vanish since the northward velocity is assumed to be zero at the boundaries. We discuss the energy equation integrated at least in the longitudinal and lateral directions in the three applications. However, the energy conversion equations averaged only in the longitudinal direction are presented in Section 3 for the application to the other problems such as meridionally propagating planetary waves.

\section{Transformed equation}

In this section I derive the transformed Eulerian-mean and eddy equation: the transformed Eulerian-mean equation is reviewed in subsection 2.1 and a transformed eddy equation required to obtain the transformed eddy energy equation consistent with the transformed mean energy equation is presented in subsection 2.2. The energy conversion equations are derived in Section 3. The ordinary equation is written down in parentheses under the corresponding trans- formed equation, by putting a suffix $b$ to the equation numbers.

\subsection{Mean equation}

The transformed Eulerian-mean flow equations in quasi-geostrophic $\beta$-plane approximation with $\log$ pressure $\left(z=H \ln \left(p_{s} / p\right)\right)$ as vertical coordinate are as follows:

$$
\begin{aligned}
& \partial \bar{u}_{0} / \partial t=-\nabla \cdot M / \rho+f \bar{v}_{1} * \\
& \left(\partial \bar{u}_{0} / \partial t=-\partial\left(\bar{v}_{0}{ }^{\prime} u_{0}{ }^{\prime}\right) / \partial y+f \bar{v}_{1}\right) \\
& \partial \bar{\phi}_{0 z} / \partial t=-N^{2} \bar{w}_{1} * \\
& \left(\partial \bar{\phi}_{z} / \partial t=-\partial\left(v_{0}{ }^{\prime} \phi_{0 z}{ }^{\prime}\right) / \partial y-N^{2} \bar{w}_{1}\right) \\
& \partial \bar{v}_{1}^{*} / \partial y+\partial\left(\rho \bar{w}_{1} *\right) / \rho \partial z=0 \\
& \left(\partial \bar{v}_{1} / \partial y+\partial\left(\rho \bar{w}_{1}\right) / \rho \partial z=0\right)
\end{aligned}
$$

where $\boldsymbol{M}$ is the E-P flux defined as

$$
\boldsymbol{M}=\left(M^{y}, M^{z}\right),
$$

where $M^{y}$ and $M^{z}$ denote northward and upward component of $M$;

$$
\begin{aligned}
& M^{y}=\overline{\rho v_{0}{ }^{\prime} u_{0}{ }^{\prime}}, \\
& M^{z}=-\rho\left(f / N^{2}\right) \overline{v_{0}{ }^{\prime} \phi_{0 z}{ }^{\prime}} .
\end{aligned}
$$

Overbars and primes denote zonal means and departures therefrom; $u, v$ and $w$ are eastward, northward and upward velocity ( 0 -suffix means the geostrophic wind such that

$$
u_{0}=-\partial \phi_{0} / f \partial y, \quad v_{0}=\partial \phi_{0} / f \partial x
$$

while 1-suffix means the non-geostrophic part of the wind); $x$ and $y$ are eastward and northward distance; $\phi$ is geopotential height; $f$ is the Coriolis parameter at a reference latitude $(y=0)$; $N$ is buoyancy frequency (assumed to be constant $) ; \rho$ is basic state density $\left(=\rho_{s} e^{-z / H}, \rho_{s}\right.$ is the density at $z=0) ; H$ is scale height. Note that the definition of E-P flux here has a sign opposite to the conventional definition used in the diagnosis of planetary waves. The definition adopted here is better from a theoretical viewpoint as discussed by Kanzawa (1982) and moreover is convenient for the present work. The residual mean meridional circulation $\left(\bar{v}_{1}{ }^{*}, \bar{w}_{1}{ }^{*}\right)$ is related to the Eulerian-mean circulation $\left(\bar{v}_{1}, \bar{w}_{1}\right)$ by the following transformations:

$$
\begin{aligned}
& \bar{v}_{1}^{*}=\bar{v}_{1}-\partial(\rho B) / \rho \partial z \\
& \bar{w}_{1} *=\bar{w}_{1}+\partial B / \partial y
\end{aligned}
$$

where

$$
B=-M^{z} / \rho f=\overline{v_{0}{ }^{\prime} \phi_{0 z}{ }^{\prime}} / N^{2} .
$$

The suffixes 0 and 1 which identify the geostrophic wind and the non-geostrophic wind will be omitted in Sections 4, 5 and 6 where the confusion may not occur and the suffixes 0 and 1 will be used for the other purposes. 
We should note the following identical relation between the E-P flux convergence and the potential vorticity transport,

$$
-\nabla \cdot \boldsymbol{M}=\rho \overline{v_{0}^{\prime} q^{\prime}}
$$

where $q$ is quasi-geostrophic potential vorticity defined as

$$
q=\zeta_{0}+\partial\left(\rho f \phi_{0 z} / N^{2}\right) / \rho \partial z
$$

where $\zeta_{0}$ is geostrophic vorticity defined as

$$
\zeta_{0}=\partial v_{0} / \partial x-\partial u_{0} / \partial y \text {. }
$$

Also note that the following identical relation between the momentum flux convergence and the vorticity transport holds:

$$
-\partial \overline{\left(v_{0}^{\prime} u_{0}^{\prime}\right)} / \partial y=\overline{v_{0}} \zeta_{0}^{\prime}
$$

which is a counterpart of Eq. (2.11). Differentiation of $(2.1)$ by $y$ yields

$$
\begin{aligned}
\partial \bar{\zeta}_{0} / \partial t & =\partial(\nabla \cdot M / \rho) \partial y-f \partial \bar{v}_{1}^{*} / \partial y \\
& =-\partial\left({\overline{v_{0}^{\prime}}}^{\prime} \bar{q}^{\prime}\right) / \partial y-f \partial \bar{v}_{1}^{*} / \partial y \\
\left(\partial \bar{\zeta}_{0} / \partial t\right) & =\partial^{2}\left({\overline{v_{0}}}^{\prime} v_{0}\right) / \partial y^{2}-f \partial \bar{v}_{1} / \partial y \\
& \left.=-\partial\left(\overline{v_{0}^{\prime} \zeta_{0}^{\prime}}\right) / \partial y-f \partial \bar{v}_{1} / \partial y\right) .
\end{aligned}
$$

Canceling the non-geostrophic wind terms in Eqs. (2.14) and (2.2) with the aid of (2.3), we cbtain the well-known conservation equation of zonal mean quasi-geostrophic potential vorticity,

$$
\begin{aligned}
\partial \bar{q} / \partial t & =-\partial \overline{\left(v_{0}^{\prime} q^{\prime}\right)} / \partial y \\
& =+\partial(\nabla \cdot M / \rho) \partial y .
\end{aligned}
$$

Eq. (2.15) is common to both the transformed form and the ordinary form since (2.15) does not include the non-geostrophic wind terms which distinguish the two forms.

\subsection{Eddy equation}

Transformed eddy equations are found to be

$$
\begin{aligned}
& \partial u_{0}{ }^{\prime} / \partial t-f v_{1}{ }^{\prime *}=-\partial \phi_{1^{\prime}} / \partial x \\
& \left(\partial u_{0}{ }^{\prime} / \partial t+\bar{u}_{0} \partial u_{0}{ }^{\prime} / \partial x-\left(\beta y-\bar{u}_{0 y}\right) v_{0}{ }^{\prime}-f v_{1}{ }^{\prime}\right. \\
& \left.\quad=-\partial \phi_{1}{ }^{\prime} / \partial x\right) . \\
& \partial v_{0}{ }^{\prime} / \partial t+\bar{u}_{0} q^{\prime}+\left(\bar{q}_{y} / f\right) \phi_{0}{ }^{\prime}+f u_{1}{ }^{*} \\
& \quad=-\partial \phi_{1}{ }^{\prime} / \partial y \\
& \left(\partial v_{0}{ }^{\prime} / \partial t+\bar{u}_{0} \partial v_{0}{ }^{\prime} / \partial x+\beta y{v_{0}}^{\prime}+f u_{1}{ }^{\prime}\right. \\
& \left.=-\partial \phi_{1}{ }^{\prime} / \partial y\right) . \\
& \partial \phi_{0 z^{\prime}} / \partial t+N^{2} w_{1}{ }^{*}=0 \\
& \left(\partial \phi_{0 z}{ }^{\prime} / \partial t+\bar{u}_{0} \partial \bar{\phi}_{0 z^{\prime}} / \partial x\right. \\
& \left.\quad+\partial \bar{\phi}_{0 z} / \partial y v_{0}{ }^{\prime}+N^{2} w_{1}{ }^{\prime}=0\right) \\
& \partial u_{1}{ }^{*} / \partial x+\partial v_{1}{ }^{*} / \partial y+\partial\left(\rho w_{1}{ }^{\prime *}\right) / \rho \partial z=0(2.19) \\
& \left(\partial u_{1}{ }^{\prime} / \partial x+\partial v_{1}{ }^{\prime} / \partial y+\partial\left(\rho w_{1}{ }^{\prime}\right) / \rho \partial z=0\right) .
\end{aligned}
$$

In the above equations the eddy-eddy interac- tion terms, e.g., $u_{0}^{\prime} \partial u_{0}^{\prime} / \partial x+v_{0}^{\prime} \partial u_{0}^{\prime} / \partial y$ are ignored: the terms do not bring about the differences between the transformed equation and the ordinary equation since the terms do not include the non-geostrophic term. The transformed nongeostrophic wind $\left(u_{1}{ }^{*}, v_{1}{ }^{\prime *}, w_{1}{ }^{\prime *}\right)$ is related to the non-geostrophic wind $\left(u_{1}{ }^{\prime}, v_{1}{ }^{\prime}, w_{1}{ }^{\prime}\right)$ by the following relation;

$$
\begin{aligned}
u_{1}{ }^{\prime *} & =u_{1}{ }^{\prime}+\left(\bar{u}_{0} \partial v_{0}{ }^{\prime} / \partial x+\beta y u_{0}{ }^{\prime}\right. \\
& \left.-\bar{u}_{0} q^{\prime}-\left(\bar{q}_{y} / f\right) \phi_{0}{ }^{\prime}\right) / f . \\
v_{1}{ }^{*} & =v_{1}{ }^{\prime}+\left(-\bar{u}_{0} \partial u_{0}{ }^{\prime} / \partial x+\left(\beta y-\bar{u}_{0 y}\right) v_{0}{ }^{\prime}\right) / f \\
w_{1}{ }^{\prime *} & =w_{1}{ }^{\prime}+\left(\bar{u}_{0} \partial{\phi_{0 z}}^{\prime} / \partial x+\partial \bar{\phi}_{0 z} / \partial y v_{0}{ }^{\prime}\right) / N^{2} \\
& =w_{1}{ }^{\prime}+\left(\bar{u}_{0} \partial v_{0}{ }^{\prime} / \partial z-\bar{u}_{0 z} v_{0}{ }^{\prime}\right) f / N^{2} .
\end{aligned}
$$

The physical meanings of the transformations (2.20)-(2.22) are not necessarily clear at the present. However, if we adopt the transformations we can obtain the transformed eddy energy equation consistent with the transformed mean energy equation, as shown in the next section. In the energy conversion equation derived in the next section, $w_{1}{ }^{\prime *}$ appears twice (see Eqs. (3.11) and (3.15)) while $v_{1}{ }^{*}$ only one (see Eq. (3.15)). In association with these circumstances, both the second and third terms in (2.22) are necessary for the consistency while only the second term is necessary in (2.21). The existence of the third term in (2.21) is irrelevant to the consistency since $v_{1}{ }^{\prime *}$ appears as the term $\phi_{0}{ }^{\prime} v_{1}{ }^{* *}$ in the energy conversion equation and the correlation of $\phi_{0}{ }^{\prime}$ and the third term in (2.21) vanishes since $\overline{\phi_{0}{ }^{\prime} v_{0}^{\prime}}=0$. If the third term is included in the transformation (2.21), Eqs. (2.16), (2.17), (2.20) and (2.23) become simpler. Therefore the third term in (2.21) has been introduced. Note $u_{1}{ }^{\prime *}$ does not appear in the energy conversion equation since the energy conversion equation integrated in the longitudinal direction is under consideration. The perturbation vorticity equation obtained from (2.16) and (2.17) with the aid of (2.7) is

$$
\begin{aligned}
& \partial \zeta_{0^{\prime}} / \partial t+\bar{u}_{0} \partial q^{\prime} / \partial x+\bar{q}_{y} v_{0}{ }^{\prime} \\
& \quad+f\left(\partial u_{1}{ }^{\prime *} / \partial x+\partial v_{1}{ }^{*} / \partial y\right)=0, \\
& \left(\partial \zeta_{0}{ }^{\prime} / \partial t+\bar{u}_{0} \partial \zeta_{0}{ }^{\prime} / \partial x+\left(\beta-\bar{u}_{0 y y}\right) v_{0}{ }^{\prime}\right. \\
& \left.\quad+f\left(\partial u_{1}{ }^{\prime} / \partial x+\partial v_{1}{ }^{\prime} / \partial y\right)=0\right) .
\end{aligned}
$$

Canceling the nongeostrophic wind terms in (2.23) and (2.18) with the aid of (2.19), we obtain the familiar equation of perturbation quasigeostrophic potential vorticity

$$
\left(\partial / \partial t+\bar{u}_{0} \partial / \partial x\right) q^{\prime}+\bar{q}_{y} v_{0}{ }^{\prime}=0 .
$$




\section{Transformed energy equation}

In this section I derive the transformed energy equation from the transformed equation presented in Section 2. Multiplying (2.1) and (2.2) by $\rho \bar{u}_{0}$ and $\rho \bar{\phi}_{0 z} / N^{2}$, and (2.16)-(2.18) by $\rho u_{0}{ }^{\prime}$, $\rho v_{0}^{\prime}$ and $\rho \phi_{0 z}{ }^{\prime} / N^{2}$ respectively, we obtain with the aid of (2.3), (2.7) and (2.19) the following energy relations:

$$
\begin{aligned}
& \partial \bar{K} / \partial t=-\left(\bar{K} \cdot K^{\prime}\right)^{*}+(\bar{P} \cdot \bar{K})^{*}+C_{\bar{K}^{*}} \\
& \left(\partial \bar{K} / \partial t=-\left(\bar{K} \cdot K^{\prime}\right)+(\bar{P} \cdot \bar{K})+C_{\bar{K}}\right) \\
& \partial \bar{P} / \partial t=-(\bar{P} \cdot \bar{K})^{*} \\
& \left(\partial \bar{P} / \partial t=-\left(\bar{P} \cdot P^{\prime}\right)-(\bar{P} \cdot \bar{K})+C_{\bar{P}}\right) \\
& \partial K^{\prime} / \partial t=\left(\bar{K} \cdot K^{\prime}\right)^{*}+\left(P^{\prime} \cdot K^{\prime}\right)^{*}+C_{K^{\prime}} * \\
& \left(\partial K^{\prime} / \partial t=\left(\bar{K} \cdot K^{\prime}\right)+\left(P^{\prime} \cdot K^{\prime}\right)+C_{K^{\prime}}\right) \\
& \partial P^{\prime} / \partial t=-\left(P^{\prime} \cdot K^{\prime}\right)^{*} \\
& \left(\partial P^{\prime} / \partial t=\left(\bar{P} \cdot P^{\prime}\right)-\left(P^{\prime} \cdot K^{\prime}\right)\right) .
\end{aligned}
$$

The notation for various energy parameters in (3.1)-(3.4) is as follows:

$$
\begin{aligned}
& \bar{K}=\rho \bar{u}_{0}{ }^{2} / 2 \\
& \bar{P}=\rho\left(\bar{\phi}_{0 z} / N\right)^{2} / 2 \\
& K^{\prime}=\rho\left(\overline{u_{0}^{\prime}}{ }^{2}+v_{0}^{\prime}{ }^{\prime 2}\right) / 2 \\
& P^{\prime}=\rho\left(\phi_{0 z}^{\prime} / N\right)^{2} / 2 \\
& \left(\bar{K} \cdot K^{\prime}\right)^{*}=\bar{u}_{0} \nabla \cdot \boldsymbol{M}=-\bar{u}_{0} \rho \overline{v_{0}^{\prime} q^{\prime}} \\
& \left(\left(\bar{K} . K^{\prime}\right)=-M^{y} \partial \bar{u}_{0} / \partial y=-\rho \overline{v_{0}^{\prime} u_{0}^{\prime}} \partial \bar{u}_{0} / \partial y\right)
\end{aligned}
$$

$$
\begin{aligned}
& (\bar{P} . \bar{K})^{*}=\rho \bar{w}_{1}{ }^{*} \bar{\phi}_{0 z} \\
& \left((\bar{P} \cdot \bar{K})=\rho \bar{w}_{1} \bar{\phi}_{0 z}\right) \\
& \left(P^{\prime} \cdot K^{\prime}\right)^{*}=\rho \bar{w}_{1}{ }^{\prime *} \phi_{0 z} \\
& \left(\left(P^{\prime} \cdot K^{\prime}\right)=\rho \bar{w}_{1^{\prime}} \phi_{0 z}{ }^{\prime}\right) \\
& C_{\bar{K}^{*}}=-\nabla \cdot \bar{W}^{*} \\
& \left(C_{\bar{K}}=-\nabla \cdot \bar{W}\right) \\
& C_{K^{\prime}}{ }^{*}=-\nabla \cdot W^{\prime *} \\
& \left(C_{K^{\prime}}=-\nabla \cdot W^{\prime}\right)
\end{aligned}
$$

where

$$
\begin{aligned}
& \bar{W}^{*}=\left(\rho \bar{\phi}_{0} \bar{v}_{1}^{*}, \rho \bar{\phi}_{0} \bar{w}_{1} *\right) \\
& \left(\boldsymbol{W}=\left(\rho \bar{\phi}_{0} \bar{v}_{1}+\boldsymbol{M}^{y} \bar{u}_{0}, \rho \bar{\phi}_{0} \bar{w}_{1}\right)\right)
\end{aligned}
$$

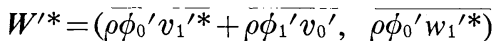

$$
\begin{aligned}
& \left(W^{\prime}=\left(\rho \overline{\phi_{0}{ }^{\prime} v_{1}{ }^{\prime}}+\rho \overline{\phi_{1}{ }^{\prime} v_{0}{ }^{\prime}}, \rho \overline{\phi_{0}{ }^{\prime} w_{1}{ }^{\prime}}\right)\right) \text {. }
\end{aligned}
$$

In the above equations $\bar{K}$ is zonal mean kinetic energy; $\overline{\boldsymbol{P}}$ is zonal mean available potential energy; $K^{\prime}$ is eddy kinetic energy; $P^{\prime}$ is eddy available potential energy. The notation (A. B)* designates a conversion of energy from type $A$ to type $\mathrm{B}$ in the transformed energetics. $\bar{W}^{*}$ and $W^{\prime *}$ mean the energy flux by mean flow and eddy motion, respectively.

The form of $(\bar{P} . \bar{K})^{*},\left(P^{\prime} . K^{\prime}\right)^{*}$ and $C_{K^{\prime}}{ }^{*}$ coincides with that of the counterparts in the ordinary energetics: if we replace the non-geostrophic wind terms $\left(v_{1}, w_{1}\right)$ with the transformed ones $\left(v_{1}{ }^{*}, w_{1}{ }^{*}\right)$ we obtain the transformed energy conversion terms. The main formal differences between the two forms lie in the energy conversion between $\bar{K}$ and $K^{\prime}$, and in that between $\bar{P}$ and $P^{\prime}$ : in the transformed form, $\left(\bar{K} \cdot K^{\prime}\right)^{*}$ explicitly includes the divergence of E-P flux or the potential vorticity transport, and the energy conversion between $\bar{P}$ and $P^{\prime}$ does not occur while in the ordinary form the conversion can occur obeying the following term,

$$
\begin{aligned}
& \left(\bar{P} . P^{\prime}\right)=-\left(\overline{\rho v_{0} \phi_{0 z}}{ }^{\prime} / N^{2}\right) \partial \bar{\phi}_{z} / \partial y \\
& \quad=-M^{z} \partial \bar{u}_{0} / \partial z .
\end{aligned}
$$

As a result of using the E-P flux and the thermal wind relation, $\left(\bar{P} . P^{\prime}\right)$ becomes to have a form similar to $\left(\bar{K} . K^{\prime}\right)$, that is,

and

$$
\left(\bar{K} . K^{\prime}\right)=-M^{y} \partial \bar{u}_{0} / \partial y
$$

$$
\left(\bar{P} . P^{\prime}\right)=-M^{z} \partial \bar{u}_{0} / \partial z .
$$

The other formal difference lies in the boundary flux terms for mean energy: Eq. (3.2b) has an extra term,

$$
\begin{aligned}
C_{\bar{P}} & =-\partial\left(\left(\rho v_{0}{ }^{\prime} \bar{\phi}_{0 z^{\prime}} / N^{2}\right) \bar{\phi}_{0 z}\right) / \partial y \\
& =\partial\left(M^{z} \bar{\phi}_{0 z} / f\right) / \partial y
\end{aligned}
$$

and the term $\bar{W}$ includes an extra quantity $M^{y} \bar{u}_{0}$. Fig. 1 illustrates the formal differences that the transformed energetics forbids the energy conversion between $\bar{P}$ and $P^{\prime}$, and also the lateral boundary flux into $\bar{P}$.

Then how are the terms $\left(\bar{P} . P^{\prime}\right)$ and $C_{\bar{P}}$ integrated to the transformed energetics? We must show the relation between the energy parameters in the transformed form and those in the ordinary form. The relation is found to be as follows:

$$
\begin{aligned}
& \left(\bar{K} \cdot K^{\prime}\right)^{*}=\left(\bar{K} \cdot K^{\prime}\right)+\left(\bar{P} \cdot P^{\prime}\right)+\nabla \cdot\left(\bar{u}_{0} M\right) \\
& (\bar{P} \cdot \bar{K})^{*}=(\bar{P} \cdot \bar{K})+\left(\bar{P} \cdot P^{\prime}\right)-C_{\bar{P}} \\
& \left(P^{\prime} \cdot K^{\prime}\right)^{*}=\left(P^{\prime} \cdot K^{\prime}\right)-\left(\bar{P} \cdot P^{\prime}\right) \\
& C_{\bar{K}^{*}}=C_{\bar{K}}+C_{\bar{P}}+\nabla \cdot\left(\bar{u}_{0} M\right)
\end{aligned}
$$

since

$$
\begin{gathered}
\bar{W}^{*}=\overline{\boldsymbol{W}}-\bar{u}_{0} \boldsymbol{M}+\left(\partial\left(\boldsymbol{M}^{z} \bar{\phi}_{0} / f\right) / \partial z\right. \\
\left.-\boldsymbol{M}^{z} \bar{\phi}_{0 z} / f,-\partial\left(\boldsymbol{M}^{z} \bar{\phi}_{0} / f\right) / \partial y\right) \\
C_{K^{\prime}} *=C_{K^{\prime}}-\nabla \cdot\left(\bar{u}_{0} \boldsymbol{M}\right)
\end{gathered}
$$

since 


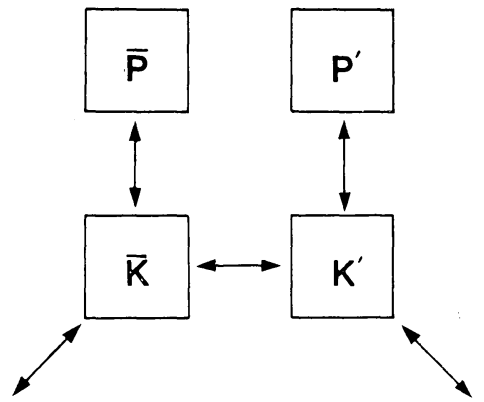

(a)

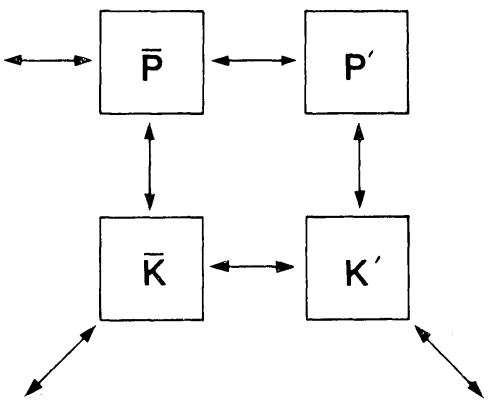

(b)

Fig. 1 Energy diagrams which illustrate the formal difference between the transformed energetics (a) and the ordinary energetics (b). The arrow with two arrowheads means the energy conversion or the boundary flux to be possible. As for the boundary flux, the slant means the boundary flux to be possible both from the lateral and vertical directions while the horizontal arrow only from the lateral direction. The diagram for the transformed energetics has no counterpart in the two places. The notations $\bar{K}, \bar{P}, K^{\prime}$ and $P^{\prime}$ designate zonal mean kinetic energy, zonal mean available potential energy, eddy kinetic ennergy and eddy available potential energy, respectively.

$$
W^{\prime *}=W^{\prime}+\bar{u}_{0} M
$$

In the transformed energetics $W^{\prime *}$ (see Eq. (3.15)) is interpreted as the wave energy flux. The wave energy flux in the transformed energetics has the relationship with the wave energy flux in the ordinary energetics $W^{\prime}$ (see Eq. (3.15b)), as expressed in Eq. (3.24), i.e.,

$$
\boldsymbol{W}^{\prime *}=\boldsymbol{W}^{\prime}+\bar{u}_{0} \boldsymbol{M} \text {. }
$$

Under the condition when the non-acceleration theorem is realized the divergence of $\boldsymbol{W}^{\prime *}$ equals zero. Therefore the circumstances that the wave does not have net influence on mean flow are directly described if we adopt $\overline{\boldsymbol{W}}^{\prime} *$ as the wave energy flux. Fig. 2 illustrates how the transformed energy conversions differ from the ordinary ones. Let the value of $\left(\bar{P} . P^{\prime}\right), \nabla \cdot\left(\bar{u}_{0} M\right)$ and $C_{\bar{P}}$ be $a, b$ and $c$ respectively. In the transformed energetics $\bar{P}$ is converted into $P^{\prime}$ through $\bar{K}$ and $K^{\prime} \quad\left(\bar{P} \rightarrow \bar{K} \rightarrow K^{\prime} \rightarrow P^{\prime} ;\right.$ see the full lines with the value $a$ in Fig. 2) instead of being converted directly (the dotted line with the value $a$ ), and the boundary flux into $\bar{K}$ provides energy for $\bar{P}$ with the energy exchange rate $c$ through the conversion between $\bar{P}$ and $\bar{K}$ (the full lines with the value $c$ ) instead of the boundary flux into $\bar{P}$ directly providing energy for $\bar{P}$. The transformed energetics has an extra energy flow (boundary $\rightarrow \bar{K} \rightarrow K^{\prime} \rightarrow$ boundary; see the full lines with the value $b$ in Fig. 2).

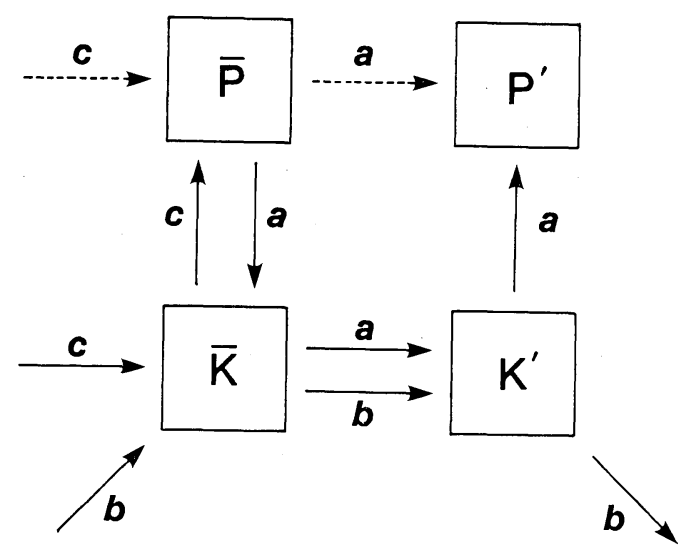

Fig. 2 Energy diagram which illustrates the actual difference between the transformed energetics and the ordinary energetics. Full lines show the extra term which the transformed energetics has while dotted lines show the term which the transformed energetics does not have. The notations $a, b$ and $c$ represent the value of $\left(\bar{P} \cdot P^{\prime}\right), \nabla$. $\left(\bar{u}_{0} M\right)$ and $C_{\bar{P}}$ respectively. (see Eqs. (3.18)-(3.24) in the text)

So far the energy is defined at a point in the meridional plane (only the zonal means are operated). We next integrate the energy equations in the region surrounded by $y=y_{1}, y_{2}$ and $z=z_{1}, z_{2}$. The boundary flux terms become 


$$
\begin{gathered}
C_{\bar{K}^{*}}=-\left.\int_{z_{1}}^{z_{2}} \rho \bar{\phi}_{0} \bar{v}_{1} * d z\right|_{y_{1}} ^{y_{2}}-\left.\int_{y_{1}}^{y_{2}} \rho \bar{\phi}_{0} \bar{w}_{1} * d y\right|_{z_{1}} ^{z_{2}} \\
C_{K^{\prime}} *=-\left.\int_{z_{1}}^{z_{2}}\left(\overline{\rho \phi_{0}^{\prime} v_{1}^{\prime *}}+\overline{\rho \phi_{1}^{\prime} v_{0}^{\prime}}\right) d z\right|_{y_{1}} ^{y_{2}} \\
-\left.\int_{y_{1}}^{y_{2}} \overline{\rho \phi_{0}^{\prime} w_{1}^{\prime *}} d y\right|_{z_{1}} ^{z_{2}}
\end{gathered}
$$

Let us impose walls on the lateral boundaries: $v_{0}=0$ and $v_{1}=0$ at $y=y_{1}, y_{2}$. All the problems to which the transformed energetics is applied in the following sections of the present paper obey this boundary condition. The transformed mean northward flow $\bar{v}_{1}^{*}=\bar{v}_{1}=0$ at the two walls since $M^{z}=0$ at the walls (see Eqs. (2.8) and (2.10)). Therefore the energy flow by mean motion from the lateral boundaries disappears. On the other hand, the transformed eddy northward wind $v_{1}{ }^{\prime *} \neq v_{1}{ }^{\prime}=0$ at the two walls (see the second term of Eq. (2.21)). However the energy flow by eddy motion from the lateral boundaries disappears since

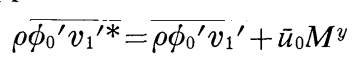

(the $y$-component of (3.24))

We also note that $C_{\bar{P}}=0$ with this boundary condition. Therefore the differences designated as the arrows with the value of $a$ and $b$ in Fig. 2 play a leading part in the discussions of the following sections.

We next impose walls on the lower and upper boundaries: $w_{1}=0$ at $z=z_{1}, z_{2}$. Eady's baroclinic instability problem obeys this boundary condition. The energy flows by mean and eddy motion from the horizontal boundaries become

$$
-\left.\int_{y_{1}}^{y_{2}} \rho \bar{\phi}_{0} \bar{w}_{1} * d y\right|_{z_{1}} ^{z_{2}}=+\int_{y_{1}}^{y_{2}} \bar{u}_{0} M^{z} d y \quad \text { (mean) }
$$

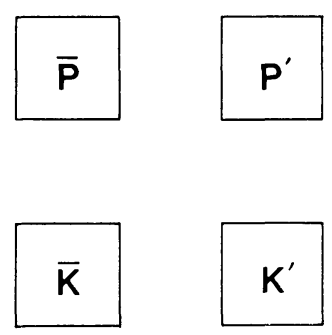

(a)

Fig. 3 Energy diagrams illustrating the situation when the non-acceleration theorem is realized for the transformed energetics (a) and for the ordinary energetics (b). and

$$
-\left.\int_{y_{1}}^{y_{2}} \rho \overline{\phi_{0}^{\prime} w_{1}{ }^{*}} d y\right|_{z_{1}} ^{z_{2}}=-\left.\int_{y_{1}}^{y_{2}} \bar{u}_{0} M^{z} d y\right|_{z_{1}} ^{z_{2}}(\text { eddy })
$$

which are generally not zero and cancel each other. If meridional eddy heat flux does not vanish with non-zero mean wind at the rigid horizontal boundaries, the energy flow at the boundaries is possible in the transformed energetics. This quality of the boundary controls the behavior of the baroclinic instability as shown in the following section. We obtain the following relation;

$$
\begin{gathered}
\partial\left(P^{\prime}+K^{\prime}\right) / \partial t=\int_{z_{1}}^{z_{2}} \int_{y_{1}}^{y_{2}} \bar{u}_{0} \nabla \cdot M d y d z \\
-\left.\int_{y_{1}}^{y_{2}} \bar{u}_{0} M^{z} d y\right|_{z_{1}} ^{z_{2}}
\end{gathered}
$$

which is essentially the same as Eq. (7.3.19) of Pedlosky (1979) who derived the equation without introducing the concept of Eliassen-Palm flux and the transformed energy flux.

In order to clarify the physical meanings of the differences between the two forms of energetics, we consider the situation in which Charney and Drazin's (1961) non-acceleration theorem is realized, that is, the vertical propagation of stationary planetary wave through a westerly mean zonal wind with positive vertical shear. The point is that the following Eliassen-Palm relation

$$
W^{\prime}=-\bar{u}_{0} M
$$

holds and

$$
\nabla \cdot M=-\overline{\rho v_{0}^{\prime} q^{\prime}}=0 .
$$

In the ordinary energetics, the energy flow is as in Fig. 3b: although the energy conversions occur

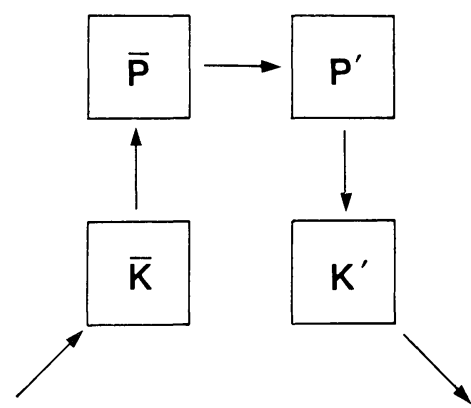

(b) 
each type of energy does not change in the result. Under the condition of negative vertical shear, the energy cycle is reversed. In the transformed energetics, the energy flow does not occur originally as displayed in Fig. 3a.

\section{Eady's baroclinic instability problem}

We apply the transformed energetics to the Eady's (1949) problem (Eady's problem is reviewed on the basis of quasigeostrophic potential vorticity equation in the two texts, Charney (1973) and Pedlosky (1979)). In Eady's simple model of baroclinic instability, the basic velocity $U$ is independent of $y$ with constant vertical shear such that

$$
U(z)=m z \text {. }
$$

The inertia density is taken as constant (Boussinesq approximation): in the basic equations of perturbations (see Eq. (2.24) with Eqs. (2.7), (2.12), and (2.13)), $\phi$ and $z$ correspond to pressure and geometric height respectively for this case. The effect of the earth's sphericity is neglected by setting $\beta$ equal to zero. The flow is confined in the lateral direction by two rigid vertical boundaries at $y=0$ and $y=L$ and also confined in the vertical direction by two rigid horizontal boundaries at $z=0$ and $z=D$.

Under these assumptions the potential vorticity gradient of the basic state identically vanishes, i.e.

$$
\bar{q}_{y}=0 \text {. }
$$

We should note that this quality of basic state indicates that the E-P flux divergence or the meridional transport of potential vorticity vanishes, i.e.

$$
\nabla \cdot M=0 \text { or } \overline{v^{\prime} q^{\prime}}=0
$$

in the inner domain since the following relation holds,

$$
v^{\prime} \bar{q}^{\prime}=-\partial \overline{\left(\eta^{\prime 2} / 2\right)} / \partial t \bar{q}_{y}
$$

where $\eta^{\prime}$ is the disturbance-associated northward particle displacement (see e.g. Pedlosky (1979)'s Eq. (7.3.26)). If we remember Eqs. (3.25) and (3.26) the wave-mean flow interaction is found to be determined by the boundary flux at $z=0$ and $z=D$ since Eq. (4.3) holds. The solution of the perturbation equation (2.24) satisfying the boundary conditions of the present problem is derived after some considerations as follows;

$$
\begin{aligned}
& \phi^{\prime}(z)=a(\sinh \mu z-(\mu \mathrm{c} / \mathrm{m}) \cosh \mu z) \\
& \quad \times e^{i k(x-c t)} \sin (\pi y / L)
\end{aligned}
$$

where $a$ is arbitrary constant with

$$
\begin{aligned}
c= & m D / 2 \pm(m / \mu)((\mu D / 2-\operatorname{coth}(\mu D / 2)) \\
& \times(\mu D / 2-\tanh (\mu D / 2)))^{1 / 2}
\end{aligned}
$$

and

$$
\mu^{2}=N^{2}\left(k^{2}+(\pi / L)^{2}\right) / f^{2} .
$$

The instability (positive imaginary $c$ ) occurs if

$$
\mu D / 2<\operatorname{coth}(\mu D / 2)
$$

i.e.

$$
\mu D<2.3994 \equiv \mu_{c} D .
$$

With use of the solution we obtain

$$
M^{y}=-\rho(\mu / N)^{2}\left(k c_{i} / 2 m\right) \sin ^{2}(\pi y / L) a^{2} e^{2 k c_{i} t} .
$$

We also obtain the wave-induced mean vertical velocity;

$$
\begin{aligned}
\bar{w} & =-(\mu / N)^{2}(\pi / f L)\left(k c_{i} / 2 m\right) a^{2} e^{2 k c_{i} l} \\
& \times\left[\sin (2 \pi y / L)+\sum_{n: \text { odd }}\left(8 / \pi\left(n^{2}-4\right)\right)\right. \\
& \times \cos (n \pi y / L) \cosh (N \pi n(z-D / 2) / f L) \\
& / \cosh (N \pi n D / 2 f L)]
\end{aligned}
$$

after some manipulation following Uryu (1979). Using the relation (2.9) we obtain the residual mean vertical velocity;

$$
\begin{aligned}
\bar{w}^{*} & =-(\mu / N)^{2}(\pi / f L)\left(k c_{i} / 2 m\right) a^{2} e^{2 k c_{i} t} \\
& \times \sum_{n: \text { odd }}\left(8 / \pi\left(n^{2}-4\right)\right) \cos (n \pi y / L) \\
& \times \cosh (N \pi n(z-D / 2) / f L) \\
& / \cosh (N \pi n D / 2 f L) .
\end{aligned}
$$

This velocity is neither the Lagrangian-mean vertical velocity nor the solenoidal part of that velocity since the waves grow in time,

Using the solutions obtained above for Eady problem, we can calculate the energy conversion terms integrated in the whole domain as follows:

$$
\begin{aligned}
& \left(\bar{K} \cdot K^{\prime}\right)^{*}=0 \\
& \left(\left(\bar{K} \cdot K^{\prime}\right)=0\right) \\
& \left(\left(\bar{P} \cdot P^{\prime}\right)=A\right) \\
& \left(P^{\prime} \cdot K^{\prime}\right)^{*}=((\mu D \operatorname{coth} \mu D-1) / 2-1) A \\
& \left(\left(P^{\prime} \cdot K^{\prime}\right)=((\mu D \operatorname{coth} \mu D-1) / 2) A\right) \\
& (\bar{P} \cdot \bar{K})^{*}=F(\varepsilon) A \\
& ((\bar{P} \cdot \bar{K})=-(1-F(\varepsilon)) A) \\
& C_{\bar{K}^{*}}=-A \\
& \left(C_{\bar{K}}=0\right) \\
& C_{K^{\prime}} *=A \\
& \left(C_{K^{\prime}}=0\right)
\end{aligned}
$$

where

$$
A=\rho(\mu / N)^{2} k c_{i} a^{2} e^{2 k c_{i} t(L D / 4)}
$$

and 


$$
F(\varepsilon)=\left(64 / \pi^{3} \varepsilon\right) \sum_{n: \text { odd }} \tanh (\varepsilon n \pi / 2) /\left(n^{3}\left(4-n^{2}\right)\right)
$$

where

$$
\varepsilon=N D / f L \text {. }
$$

Note that all the energy conversion terms are proportional to $A$ and $A=0$ when $c_{i}=0$. Therefore the energy conversion does not occur irrespective of the kind of energetics we adopt when the wave considered is not unstable. Under the instability condition we can readily obtain the inequality

$$
0<(\mu D \operatorname{coth} \mu D-1) / 2<1
$$

which shows

$$
\left(P^{\prime} . K^{\prime}\right)^{*}<0 \text { and }\left(P^{\prime} . K^{\prime}\right)>0 .
$$

We can also find the inequality after some manipulation

$$
0<F(\varepsilon)<1
$$

which shows

$$
(\bar{P} . \bar{K})^{*}>0 \text { and }(\bar{P} . \bar{K})<0 \text {. }
$$

The situations are illustrated in Fig. 4. The energy flows as

$$
\text { Boundary } \rightarrow K^{\prime} \rightarrow P^{\prime}
$$

and

$$
\bar{P} \rightarrow \bar{K} \rightarrow \text { Boundary }
$$

in the transformed energetics while

$$
\bar{K} \rightarrow \bar{P} \rightarrow P^{\prime} \rightarrow K^{\prime}
$$

in the ordinary energetics. In the transformed energetics, the horizontal boundary supplies energy for the kinetic energy of waves and a part of the energy transfers from the kinetic energy of waves into the potential energy of waves. The wave-induced direct mean meridional circulation brings about the energy conversion from the mean potential energy to the mean kinetic energy and gives energy to the horizontal boundary. It is well known that the existence of the rigid horizontal boundary plays an essential role in producing baroclinic instability except the internal jet instability treated by Charney and Stern (1962). The transformed energetics explicitly describes the role of the boundary. It seems to be strange that the rigid horizontal plane boundaries perform work. However, if we adopt Bretherton's (1966) view that temperature gradients on a rigid horizontal boundary are replaced by gradients of quasi-geostrophic potential vorticity concentrated in sheets just within the fluid, we can consider that the potential vorticity sheets along the boundaries perform work. In the present problem, the transformed (a)
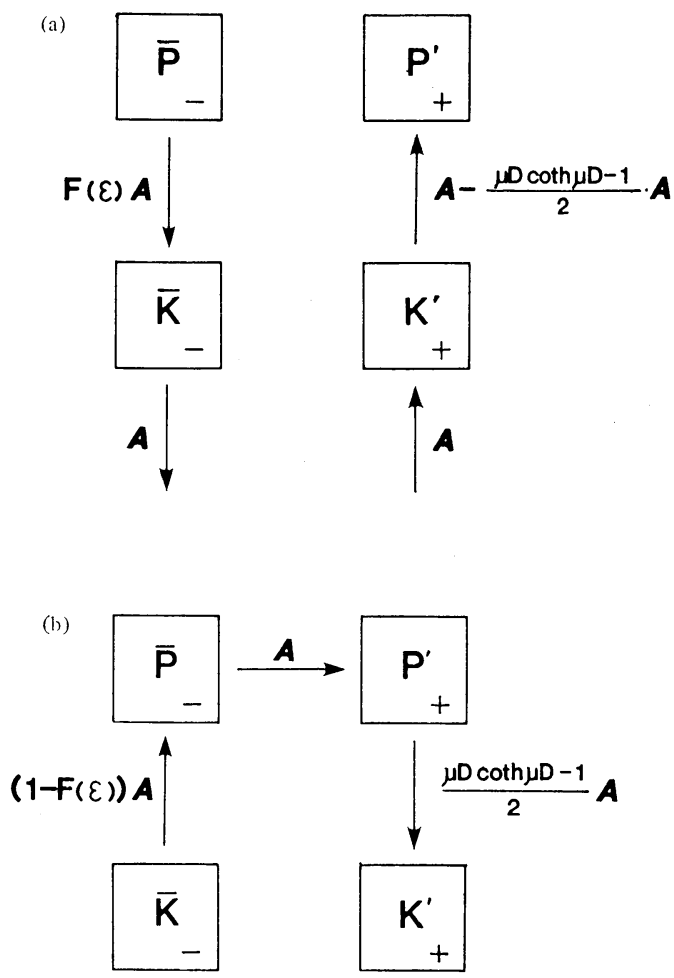

Fig. 4 Energy diagrams illustrating how the energy converts in case of Eady's baroclinic instability problem in the transformed energetics (a) and in the ordinary energetics (b). The definitions of $A, F(\varepsilon)$ and $\mu D$ are shown in the text. The notation + and in the box mean whether the type of energy has a tendency to increase or decrease.

mean and eddy vertical velocities have non-zero value in the upper and lower potential vorticity sheets since temperature is inhomogeneous at the boundaries (see Eqs. (2.9) and (2.22)). Therefore the vorticity sheets can perform work. The residual mean vertical velocities at the boundaries are as follows;

$$
\begin{gathered}
\bar{w}^{*}(z=0)=\bar{w}^{*}(z=D)=(\mu / N)^{2}(\pi / f L) \\
\times\left(k c_{i} / 2 m\right) a^{2} e^{2 k c_{i} t} \sin (2 \pi y / L)
\end{gathered}
$$

which is obtained from Eq. (4.11). In the northern hemisphere (the Coriolis parameter $f$ is positive), the direction of the residual mean vertical velocities at the boundaries is upward in the southern half part while downward in the northern half part. The mass conservation in the meridional domain is considered to be achieved by the residual mean meridional flow in the potential vorticity sheet: southward flow at the bottom sheet and northward flow at the 
top sheet. The residual mean meridional circulation is the direct circulation which consists of three cells. One cell occupies the whole meridional plane while the other two cells in the central part of the upper and lower half plane (not shown).

In the present wind profile energy is supplied by the upper horizontal boundary where $U=m D$ not by the lower boundary where $U=0$ (see Eqs. (3.25) and (3.26)). The non-zero eddy energy flux comes from the advection of temperature by the mean wind (see the second term of the right hand side of Eq. (2.22)). Therefore the eddy energy flux becomes zero at the lower boundary without the advection of temperature. The energy flux by the mean motion is zero at the lower boundary where $\bar{\phi}$ is independent of $y$. If we add a constant value to the basic linear shear wind expressed by Eq. (4.1) the input and output of energy at the boundaries change although the net gain of energy does not change, as Eq. (3.26) shows.

\section{Upward propagating planetary wave incident on a critical level}

We consider the situation that a stationary planetary wave propagates upward into a critical level as illustrated in Fig. 5. This situation was investigated in Matsuno and Nakamura (1979) (hereafter referred to as $\mathrm{MN}$ ) with special attention to the induced mean meridional circulation during a sudden stratospheric warming. In this

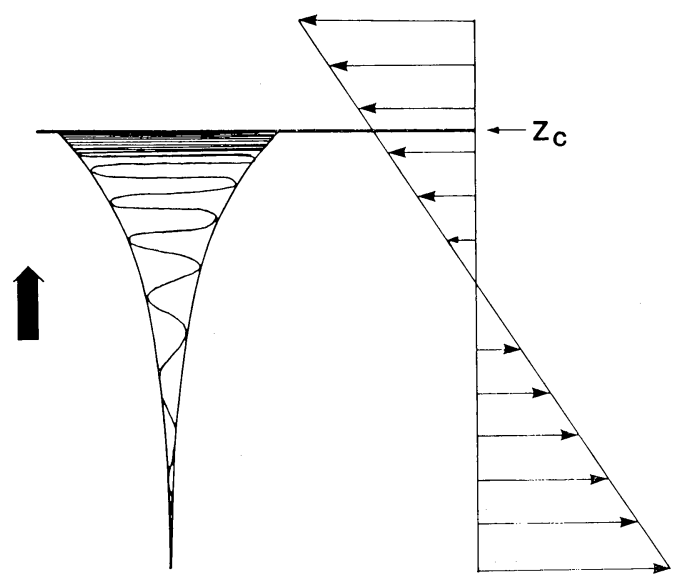

Fig. 5 Schematic illustration of upward propagating planetary wave incident on a critical level designated as $z_{c}$. Planetary wave has the amplitude which decays exponentially downward from the critical level and the vertical wavelength which approaches zero near the critical level. section I will try to analyze the energetics of this situation using the solution of MN. In order to analyze the energetics we must give a concrete profile to the basic wind $U$ although MN need not do so for their purpose. We give the simplest profile to the mean wind $U(z)$ which has a critical level, i.e., the negative constant vertical shear such that

$$
U(z)-c=-m\left(z-z_{c}\right)
$$

where $m$ is a positive constant, $c$ is the zonal phase velocity of the wave and $z_{c}$ is the height of the critical level. We give two rigid walls at $y=0$ and $y=L$. Therefore the basic geopotential height becomes

$$
\bar{\phi}=f m\left(\left(z-z_{c}\right)-c / m\right)(y-L / 2)
$$

and

$$
\bar{\phi}_{z}=f m(y-L / 2) .
$$

The solutions of MN required to our discussion are briefly reviewed. As a solution of the wave equation (2.24), we consider the form

$$
\phi^{\prime}=\Phi(z) \sin (\pi y / L) e^{i k(x-c t)} .
$$

After some manipulation we obtain

$$
\begin{aligned}
& M^{z}=-\rho\left(z_{c}\right)\left(Q_{0} / N\right) \sin ^{2}(\pi y / L) \boldsymbol{H}\left(z_{c}-z\right) \\
& \bar{w}=-\left(\pi Q_{0} / f N L\right)\left[e^{\left(z-z_{c}\right) / H} \sin (2 y / L) H\left(z_{c}-z\right)\right. \\
& \left.\quad+\sum_{n: \text { odd }}\left(4 / \pi \mu_{n}\left(n^{2}-4\right)\right) d G_{n} / d z \cos (n \pi y / L)\right]
\end{aligned}
$$

where $\boldsymbol{H}(x)$ is the Heaviside step function, defined as

$$
\begin{aligned}
& \boldsymbol{H}(x)= \begin{cases}0, & x<0 \\
1, & x \geq 0\end{cases} \\
& G_{n}(z)= \begin{cases}e^{\left(1 / 2 H-\mu_{n}\right)\left(z-z_{c}\right)}, & z>z_{c} \\
e^{\left(1 / 2 H+\mu_{n}\right)\left(z-z_{c}\right)}, & z<z_{c}\end{cases} \\
& \mu_{n}=\left(1 / 4 H^{2}+(N \pi / f L)^{2} n^{2}\right)^{1 / 2}
\end{aligned}
$$

and

$$
\begin{aligned}
Q_{0} & =\left(\pi N k / 2 f^{2}\right)\left(\bar{q}_{y}|\Phi|^{2} / \partial U / \partial z\right)_{z} \\
& =\left(\pi N k / 2 f^{2} m\right)\left(\bar{q}_{y}|\Phi|^{2}\right)_{z} .
\end{aligned}
$$

Eq. (5.4) shows that the vertical component of E-P flux has a constant negative value (northward eddy heat flux) below the critical level and becomes zero after passing through the critical level. Therefore the convergence of E-P flux becomes negative infinite (i.e., infinite southward potential vorticity transport) at the critical level, which brings about the westward acceleration of mean flow. Using the relation (2.9) we obtain the vertical component of the residual mean meridional circulation as follows; 


$$
\begin{aligned}
\bar{w}^{*} & =-\left(\pi Q_{0} / f N L\right) \sum_{n: \text { odd }}\left(4 / \pi \mu_{n}\left(n^{2}-4\right)\right) \\
& \times d G_{n} / d z \cos (n \pi y / L) .
\end{aligned}
$$

It is noted here that the residual mean meridional circulation coincides with the Lagrangianmean meridional circulation as MN's Eq. (4.16) shows. The two meridional circulations for the present problem are displayed in MN's Figs. 3 and 5: the ordinary Eulerian-mean meridional circulation assumes the direct circulation (the upward motion occurring in the warmer high latitudes while the downward motion in the colder lower latitudes) and the residual mean meridional circulation (i.e., Lagrangian-mean meridional circulation in this case) assumes the indirect circulation below the critical level while the direct circulation above the critical level.

Using these solutions we obtain the following energy parameters for the whole domain;

$$
\begin{aligned}
& \left(\bar{K} \cdot K^{\prime}\right)^{*}=B \\
& \left(\left(\bar{K} \cdot K^{\prime}\right)=0\right) \\
& \left(\left(\bar{P} \cdot P^{\prime}\right)=A\right) \\
& \left(P^{\prime} \cdot K^{\prime}\right)^{*}=0 \\
& \left(\left(P^{\prime} \cdot K^{\prime}\right)=A\right) \\
& (\bar{P} \cdot \bar{K})^{*}=C \\
& ((\bar{P} \cdot \bar{K})=-A+C) \\
& C_{K^{\prime}} *= \\
& \left(C_{K^{\prime}}=-A+B\right) \\
& C_{\bar{K}^{*}}=0 \\
& \left(C_{\bar{K}}=A-B\right)
\end{aligned}
$$

where

$$
\begin{aligned}
A & =\int_{-\infty}^{+\infty} \int_{0}^{L}-M^{z} \partial U / \partial z d y d z \\
& =\int_{-\infty}^{+\infty}-\rho\left(z_{c}\right)\left(m Q_{0} / N\right)(L / 2) H\left(z_{c}-z\right) d z \\
& =-\infty \\
B= & \int_{-\infty}^{+\infty} \int_{0}^{L} U \partial M^{z} / \partial z d y d z=\rho\left(z_{c}\right)\left(Q_{0} / N\right)(L / 2) \\
& \times \int_{-\infty}^{+\infty} U(z) \delta\left(z-z_{c}\right) d z \\
& =U\left(z_{c}\right) \rho\left(z_{c}\right)\left(Q_{0} / N\right)(L / 2) \\
& =c \rho\left(z_{c}\right)\left(Q_{0} / N\right)(L / 2) \\
C= & \rho\left(z_{c}\right)\left(m Q_{0} / N\right)(f L / N \pi)^{2}(L / \pi H) \\
& \times \sum_{n: \text { odd }}\left(16 / \pi\left(n^{2}-4\right) n^{4}\right)
\end{aligned}
$$

Fig. 6 shows the behavior of the energy transfer for the case of the wave phase velocity $c=0$ in which the critical level coincides with (a)

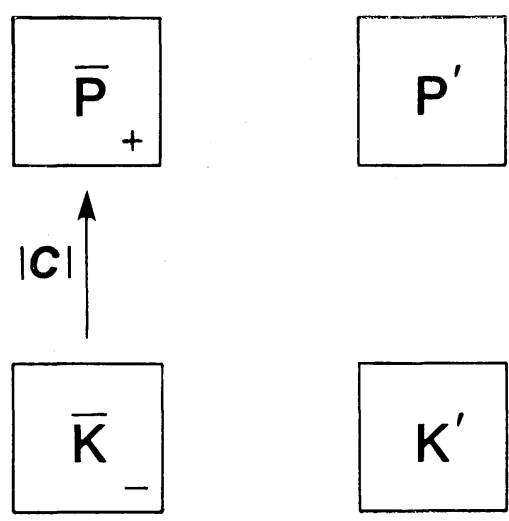

(b)
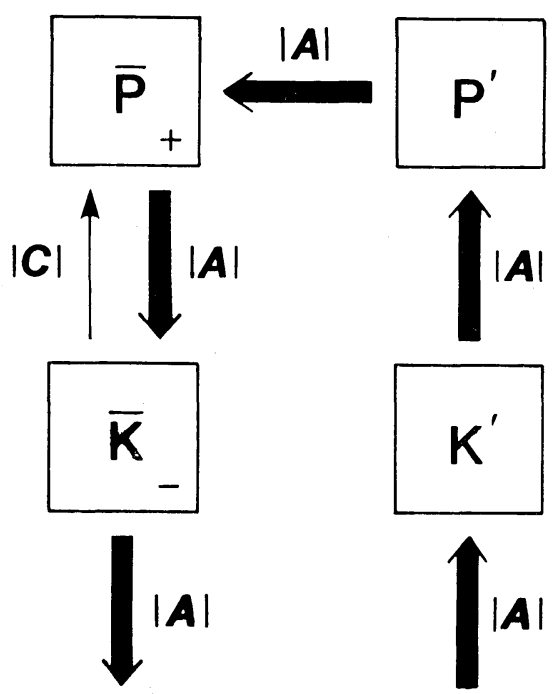

Fig. 6 Energy diagrams illustrating how the energy converts for the problem of upward propagating planetary wave incident on a critical level in the transformed energetics (a) and in the ordinary energetics (b) in case of $U\left(z_{c}\right)=c=0$. The definitions of $A$ and $C$ are shown in the text. The notations + and - in the box mean whether the type of energy has a tendency to increase or decrease.

the level of the zero wind line. Since $B=0$ in this case as Eq. (5.17) shows, $\left(\bar{K} \cdot K^{\prime}\right)^{*}=0$. In the transformed energetics energy is transferred from the mean kinetic energy to the mean potential energy by the indirect meridional circulation below the critical level. Although the direct meridional circulation occurs above the critical level, the effect of the direct circulation on the energy conversion is smaller than that of the 
indirect circulation because of the inertia density stratification. In the ordinary energetics the infinite energy transfer $A$, which does not have net influence on the budget of energy in the result, is added to the energy cycle. Therefore in the ordinary energetics energy is transferred from the mean potential energy to the mean kinetic energy by the direct meridional circulation. However the mean potential energy has a tendency to increase as a result of receiving more energy from the eddy potential energy while the mean kinetic energy have a tendency to decrease as a result of releasing more energy to infinity below the critical level. Thus the transformed energetics gives a simpler picture to the process occurring. The fact that the mean kinetic energy has a tendency to decrease is easily understood from the following deduction: since almost in the domain the zonal mean acceleration is negative (see Fig. 1 of $\mathrm{MN}$ ) the mean kinetic energy has a tendency to decrease below the critical level where the basic mean wind is originally positive. The tendency to decrease has more weight than the tendency to increase above the critical level because of the inertia density stratification. It is noted that for Boussinesq fluid, that is, for the fluid without the inertia density stratification $C=0$ since the Boussinesq assumption corresponds to putting the density scale height $H$ into infinite (see Eq. (5.18)). Therefore the energy transfer does not occur for Boussinesq fluid in the transformed energetics.

Fig. 7 shows the behavior of the energy transfer in case of the negative phase velocity. In this case $B$ is negative since the basic wind at the critical level is negative. Therefore the energy conversion from the eddy kinetic energy to the mean kinetic energy is added to the $c=0$ case in the transformed energetics. Note that whether the energy conversion between the mean kinetic energy and the eddy kinetic energy in the transformed energetics occurs or not is determined by whether the basic wind at the critical level (i.e., the wave phase velocity) is zero or not relative to the rotating earth. In the ordinary energetics, to the $c=0$ case is added the energy supply to the mean kinetic energy and the energy release from the eddy kinetic energy by the work done at infinity below the critical level. Even for Boussinesq case B does not vanish. Therefore the energy conversions added to the $c=0$ case which are described above remain for Boussinesq fluid. (a)

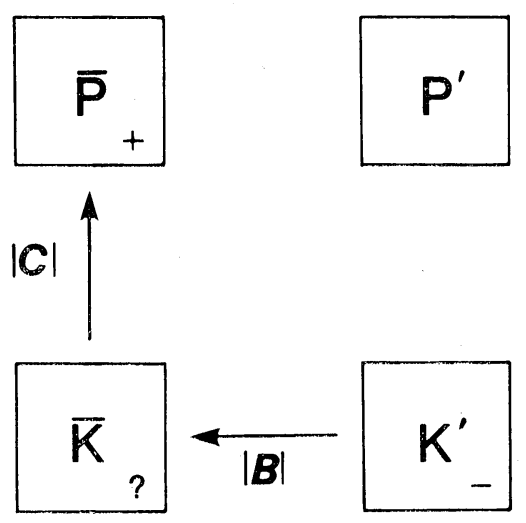

(b)
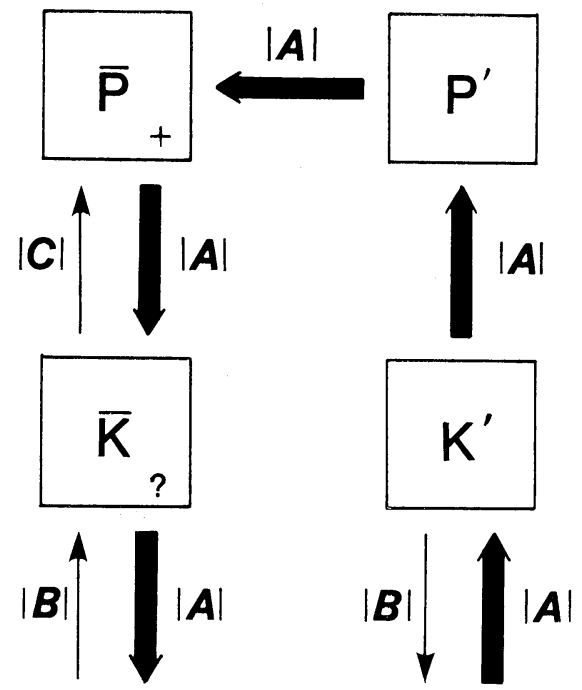

Fig. 7 Same as in Fig. 6 but for $U\left(z_{c}\right)=c<0$. The notation? in the box of $\bar{K}$ means that whether $\bar{K}$ increases or not depends on the situation.

\section{Upward propagating Rossby wave packet}

We consider the situation that Rossby wave packet is propagating upward as illustrated in Fig. 8. The problem of vertically propagating Rossby wave packet was investigated by Uryu (1974) in terms of the wave momentum transport. In this section I will try to analyze the energetics of the wave packet using the solutions of Uryu. We use nondimensional variables scaled by suitable characteristic scales, following Uryu who used two-scale methods. We consider the Boussinesq fluid bounded by two rigid walls at $y=0$ and $y=1$. As already stated in Section 4 , the geopotential $\phi$ and the log-pressure height 


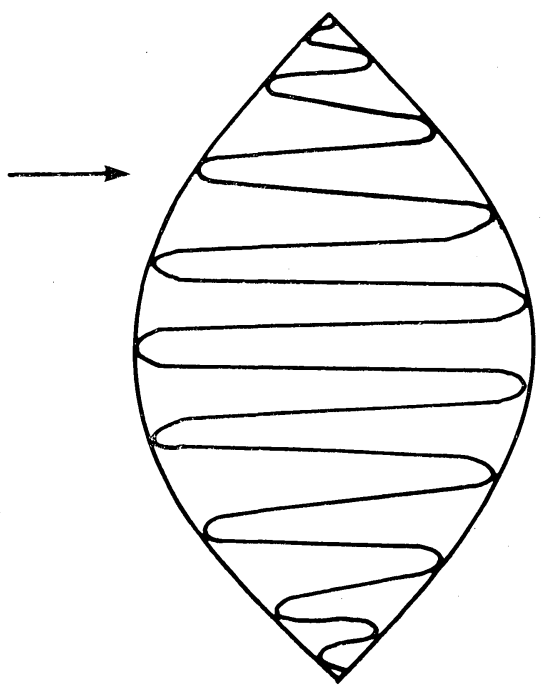

Fig. 8 Schematic illustration of upward propagating Rossby wave packet. The energy conversion is evaluated at a point fixed in the space in the upper half part of the packet (see a thin horizontal arrow).

$z$ in Sections 2 and 3 are interpreted as pressure and geometric height respectively. There we use the notation $p$ in place of $\phi$. When we treat the energetics the problem of stationary wave propagation through the basic field with a constant westerly wind is not the same as that of westward propagation of steady wave through the zero wind even if the two problems seem to be same from the viewpoint of momentum: the latter case was treated by Uryu. Therefore we will add the basic wind to Uryu's problem, that is, we separate pressure $p$ into four parts as follows;

$$
p=P_{00}-U(y-1 / 2)+p^{\prime}+\bar{P} .
$$

The first and the second term is the basic timeindependent term (the second term is corresponding to the added basic wind), the third is the wave packet part and the fourth is the wave-induced mean pressure.

In order to proceed to the energetics we must briefly review the solutions of Uryu. The wave packet is assumed to have following form;

$$
p^{\prime}=a \sin \pi y \operatorname{Re}\left(P(z, T) e^{i(k x+n z-\sigma t)}\right) .
$$

where $T$ and $Z$ are the slow variables defined as

$$
T=\varepsilon t . \quad Z=\varepsilon Z
$$

where $\varepsilon$ is a small parameter characterizing the slowness of the variation of the wave envelope $P(Z, T)$. The wave-induced mean pressure is assumed to vary slowly in the same time and vertical scales as the wave envelope, i.e.

$$
\bar{P}=\bar{P}(y, z, T) \text {. }
$$

$P$ and $\bar{P}$ are expanded by $\varepsilon$ as follows;

$$
\begin{aligned}
& P=P_{0}+P_{1}+\cdots \\
& \bar{P}=\bar{P}_{0}+\bar{P}_{1}+\cdots
\end{aligned}
$$

From the basic equation (2.24), the wave packet solution is obtained as

$$
\left(\partial / \partial T+c_{g} \partial / \partial Z\right) P_{0}=0: 0\left(\varepsilon^{1}\right)
$$

where $c_{g}$ is the vertical group velocity of the wave packet given by

$$
c_{g}=-2 \sigma^{*} n /\left(k^{2}+\pi^{2}+n^{2}\right)
$$

where

$$
\sigma^{*}=\sigma-k U=-\beta k /\left(k^{2}+\pi^{2}+n^{2}\right): 0\left(\varepsilon^{0}\right)(6.8)
$$

which is the dispersion relation. The group velocity $c_{g}$ is positive for the upward propagating wave packet ( $n$ is positive) under consideration. The equation (6.6) leads to the wave energy conservation in the propagating process, i.e.,

$$
\left(\partial / \partial T+c_{g} \partial / \partial Z\right) E_{0}=0
$$

where $E_{0}$ is the wave energy

$$
E_{0}=a^{2}(1 / 8)\left(k^{2}+\pi^{2}+n^{2}\right)\left|P_{0}\right|^{2}: 0\left(\varepsilon^{0}\right),
$$

which is the total of the kinetic energy and available potential energy of the wave. The vertical component of E-P flux is found to be

$$
M^{z}=-a^{2}(k n / 2) \sin ^{2}(\pi y)\left|P_{0}\right|^{2}
$$

The wave-induced mean motion is obtained as follows:

$$
\begin{aligned}
U_{0} & =(1-\cos 2 \pi y)\left\langle U_{0}\right\rangle \\
P_{0} & =(1 / 2-y+\sin 2 \pi y / 2)\left\langle U_{0}\right\rangle \\
W_{0} & =2 \pi \sin 2 \pi y c_{g}\left\langle U_{0}\right\rangle \\
& =-a^{2}(k n \pi / 2) \sin (2 \pi y)\left|P_{0}\right|^{2}
\end{aligned}
$$

where $\left\langle U_{0}\right\rangle$ is the induced momentum such as

$$
\left\langle U_{0}\right\rangle=E_{0} /(c-U) \text {. }
$$

The notation $\langle>$ means the average with respect to the $y$-direction. Eqs. (6.11) and (6.14) with use of Eq. (2.9) yield

$$
\bar{W}_{0} *=0
$$

Namely, the residual mean vertical velocity which is equal to Lagrangian-mean vertical velocity in this case vanishes.

Using the above solutions we obtain the following energy conversion terms after integrated only with respect to the $y$-direction;

$$
\begin{aligned}
& \left(\bar{K} \cdot K^{\prime}\right)^{*}=B-a^{2}(k U n / 4) \partial\left|P_{0}\right|^{2} / \partial Z \\
& \left(\left(\bar{K} \cdot K^{\prime}\right)=0\right),
\end{aligned}
$$




$$
\begin{array}{lr}
\left(\left(\bar{P} . P^{\prime}\right)=A\right), & (6.17) \\
\left(P^{\prime} . K^{\prime}\right)^{*}=-a^{2}\left(n^{2} / 8\right) \partial\left|P_{0}\right|^{2} / \partial T & (6.18) \\
\left(\left(P^{\prime} . K^{\prime}\right)=A-a^{2}\left(n^{2} / 8\right) \partial\left|P_{0}\right|^{2} / \partial T\right), & (6.18 \mathrm{~b}) \\
(\bar{P} . \bar{K})^{*}=0 & (6.19) \\
((\bar{P} . \bar{K})=-A), & (6.19 \mathrm{~b}) \\
C_{K^{\prime}} *=-\partial W^{\prime *} / \partial Z=a^{2}(\sigma n / 4) \partial\left|P_{0}\right|^{2} / \partial Z & (6.20) \\
\left(C_{K^{\prime}}=-\partial W^{\prime} / \partial Z\right. & (6.20 \mathrm{~b}) \\
\left.\quad=-A+B+a^{2}\left(\sigma^{*} n / 4\right) \partial\left|P_{0}\right|^{2} / \partial Z\right), \\
C_{\bar{K}^{*}}=-\partial \bar{W} * / \partial Z=0 \\
\left(C_{\bar{K}}=-\partial \bar{W} / \partial Z\right. \\
\left.\quad=A-B+a^{2}(k U n / 4) \partial\left|P_{0}\right|^{2} / \partial Z\right), & (6.21 \mathrm{~b}) \\
W^{*}=-a^{2}(\sigma n / 4)\left|P_{0}\right|^{2} & (6.22) \\
\left(W^{\prime}=a^{2}\left(3 k n / 8\left\langle U_{0}\right\rangle\left|P_{0}\right|^{2}-a^{2}\left(\sigma^{*} n / 4\right)\left|P_{0}\right|^{2}\right),\right. & (6.22 \mathrm{~b}) \\
\bar{W}^{*}=0 & (6.23) \\
\left(\bar{W}=-a^{2}(3 k n / 8)\left\langle U_{0}\right\rangle\left|P_{0}\right|^{2}-a^{2}(k U / 4)\left|P_{0}\right|^{2}\right),
\end{array}
$$

where

$$
A=\varepsilon a^{2}(3 k n / 8)\left|P_{0}\right|^{2} \partial\left\langle U_{0}\right\rangle / \partial Z
$$

and

$$
B=-\varepsilon a^{2}(3 k n / 8)\left\langle U_{0}\right\rangle \partial\left|P_{0}\right|^{2} / \partial Z,
$$

We note thet $\bar{K}, K^{\prime}, \bar{P}$ and $P^{\prime}$ change with time of $O(\varepsilon)$ as follows:

$$
\begin{aligned}
\varepsilon \cdot \partial K^{\prime} / \partial T= & \varepsilon a^{2}\left(k^{2}+\pi^{2}\right) / 8 \cdot \partial\left|P_{0}\right|^{2} / \partial T+B \\
\varepsilon \cdot \partial P^{\prime} / \partial T= & \varepsilon a^{2} n^{2} / 8 \cdot \partial\left|P_{0}\right|^{2} / \partial T \\
\varepsilon \cdot \partial \bar{K} / \partial T= & a^{2}\left(k U / 8 \sigma^{*}\right)\left(k^{2}+\pi^{2}+n^{2}\right) \\
& \times \partial\left|P_{0}\right|^{2} / \partial T-B \\
\varepsilon \cdot \partial \bar{P} / \partial T= & 0 .
\end{aligned}
$$

In the right hand sides of the equations (6.16)(6.21), the terms designated by $A$ and $B$ are of $O\left(a^{4}\right)$ since $\left\langle U_{0}\right\rangle$ is $O\left(a^{2}\right)$ (see Eqs. (6.15) and (6.10)) and the other terms explicitly written down are of $O\left(a^{2}\right)$. The zonal mean kinetic energy $\bar{K}$ is as follows:

$$
\begin{aligned}
\bar{K} & =\left\langle\left(U+\bar{U}_{0}\right)^{2} / 2\right\rangle \\
& =U^{2} / 2+U\left\langle U_{0}\right\rangle+3\left\langle U_{0}\right\rangle^{2} / 4,
\end{aligned}
$$

where we use Eq. (6.12). Therefore

$$
\partial \bar{K} / \partial T=U \cdot \partial\left\langle U_{0}\right\rangle / \partial T+(3 / 4) \partial\left\langle U_{0}\right\rangle^{2} / \partial T .
$$

The first term of the right hand side of the above equation is of $O\left(a^{2}\right)$ while the second term is of $O\left(a^{4}\right)$. Each term is corresponding to the term of $O\left(a^{2}\right)$ or $O\left(a^{4}\right)$ in the right hand side of
Eq. (6.28).

We consider the situations in the upper half part of the upward propagating wave packet (see Fig. 8) where

$$
\partial\left|P_{0}\right|^{2} / \partial T>0 \text { and } \partial\left|P_{0}\right|^{2} / \partial Z<0
$$

for the two cases, i.e.,

case 1: $\quad U=0$ and $\sigma^{*}=\sigma_{1}<0$

and

case 2: $\quad U=U_{2}>0$ and $\sigma=0\left(U_{2}\right.$ is such that $\left.\sigma^{*}=-k U_{2}=\sigma_{1}\right)$.

Both cases are of the same situation from the viewpoint of momentum since the intrinsic wave frequency $\sigma^{*}$ is the same. The energy conversions for cases 1 and 2 are illustrated in Figs. 9 and 10 respectively. For case 1 energy is supplied by the energy flux convergence to the eddy kinetic energy and then is transferred to the eddy available potential energy in $O\left(a^{2}\right)$ : the situation is the same both for the transformed energetics and for the ordinary energetics in $O\left(a^{2}\right)$. Since $U=0,\left(\bar{K} . K^{\prime}\right)^{*}=0, C_{K^{\prime}} *=C_{K^{\prime}}$ and $C_{\bar{K}}=0$ in $O\left(a^{2}\right)$. The eddy energy can increase since a more energtic part of the wave packet comes into the region considered. The behavior of energy transfer in $O\left(a^{4}\right)$ is simpler in the transformed energtics than in the ordinary energetics. The mean kinetic energy has a tendency to increase by the energy transfer from the eddy kinetic energy in the transformed energetics while in the ordinary energetics since the energy flux convergence supplies more energy than the energy release to the mean potential energy. These $O\left(a^{4}\right)$ terms appear by the interaction between the wave flux and the wave-induced mean flow. For case 2 in $O\left(a^{2}\right)$ the eddy kinetic energy receives energy from the zonal mean kinetic energy in the transformed energetics while from the energy flux convergence in the ordinary energetics. Since $\sigma=0, C_{K^{\prime}} *=0\left(W^{\prime *}=0\right)$ and $C_{K^{\prime}}$ $=-C_{\vec{K}}$ in $O\left(a^{2}\right)$. The transformed energetics well reflects the fact that in case 2 the mean flow has a reservoir of kinetic energy.

\section{Discussion}

It is well known that the existence of rigid horizontal boundaries with non-vanishing meridional gradient of zonal mean temperature (i.e., vertical gradient of zonal mean wind) causes baroclinic instability. The circumstances are explicitly described by the transformed energetics while not by the ordinary energetics: the eddy receives kinetic energy through the "work" done by the potential vorticity sheets along the boundary against the fluid through the eddy motion in 
(a)
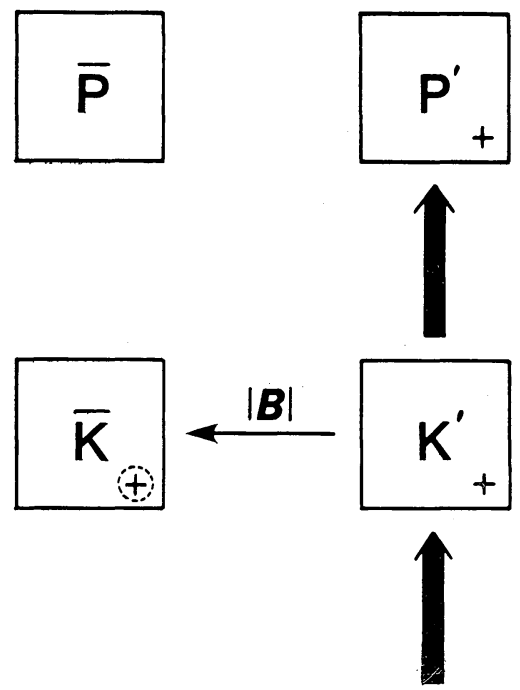

(b)

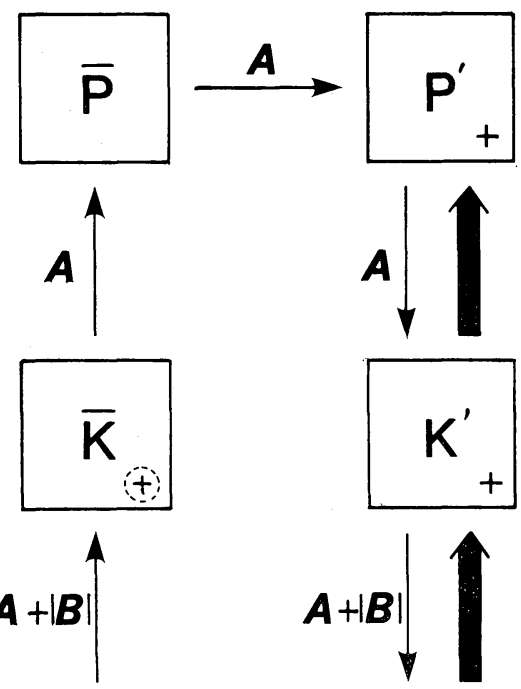

Fig. 9 Energy diagrams illustrating how the energy converts in the upper half part of the upward propagating Rossby wave packet in the transformed energetics (a) and in the ordinary energetics (b) in case of $U=0$ and $\sigma<0\left(\sigma^{*}=\sigma_{1}\right)$. Thick arrows means the magnitude of $O\left(a^{2}\right)$ while thin arrows of $O\left(a^{4}\right)$. The definitions of $A$ and $B$ are shown in the text. About the quantity designated as the thick arrows see also the text. The notations + and - in the box mean whether the type of energy has a tendency to increase or decrease. The notation + surrounded by a dotted circle means that this tendency is of $O\left(a^{4}\right)$. (a)
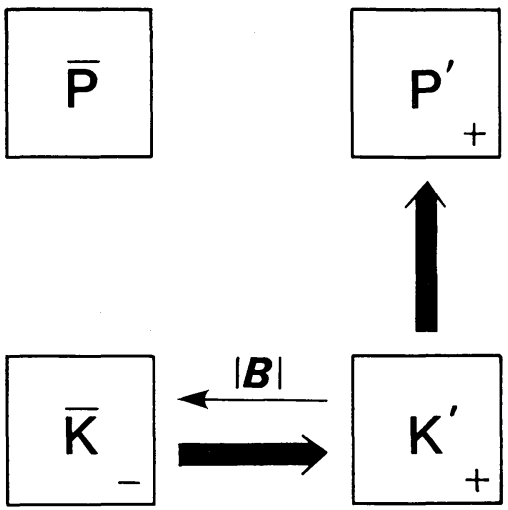

(b)
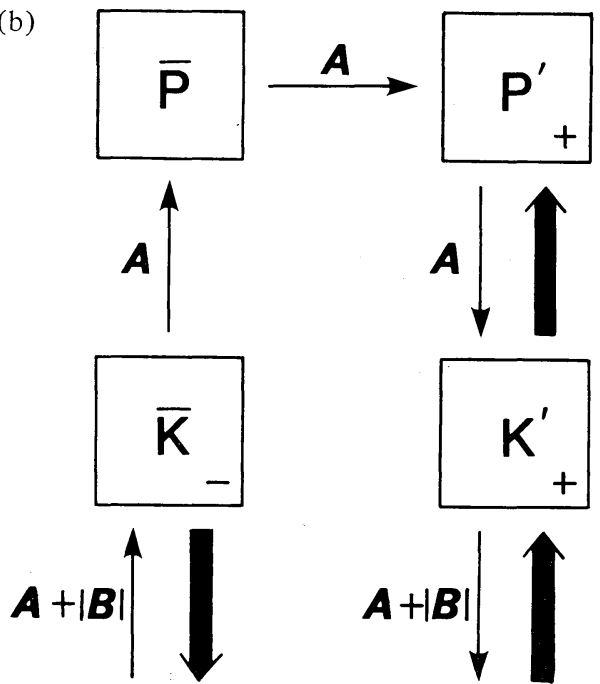

Fig. 10 Same as in Fig. 9 but for $U=U_{2}>0$ and $\sigma=0\left(\sigma^{*}=-k U_{2}=\sigma_{1}\right)$.

the transformed energetics. This view is different from the conventional view of the ordinary energetics that the unstable waves grow by eating the mean available potential energy. I think that both views contribute to understanding of the Eady's problem.

For both upward propagating planetary wave incident on a critical level and upward propagating planetary wave packet, the behavior of the energy conversions is simpler in the transformed energetics than in the ordinary energetics since in the transformed energetics there is originally no conversion which does not have net influence on the budget of the four types of energy first defined by Lorenz (1955). For these wave propagation problems, total wave 
energy (kinetic energy plus available potential energy) is usually referred to while in the present paper wave energy is separated into the two parts. The quantity irrelevant to the net budget of energy is the vertical component of E-P flux multiplied by the vertical gradient of mean wind, that is, the meridional eddy heat flux multiplied by the meridional gradient of mean temperature.

We considered the two cases which can not be distinguished from the viewpoint of momentum both for the critical level problem and for the wave packet problem. The behavior of energy transfer differs each other: the energy conversion between the mean kinetic energy and the eddy kinetic energy occurs in one case and does not occur in another case in the transformed energetics while the extra wave energy flux convergence is added or not in the ordinary energetics. This difference comes from the definition of the mean kinetic energy: the magnitude of kinetic energy of mean flow changes, depending on which frame of reference moving with a constant speed we adopt. This ambiguity of the energetics can not be removed by the transformed energetics as long as the definition of the mean kinetic energy itself remains as it is. This weak point of the energetics itself is intensively discussed by Uryu (1976). Moreover, Uryu derived through some reasoning the quantity $F$ for internal gravity waves such as

$$
F=\overline{p^{\prime} w^{\prime}}+U \overline{u^{\prime} w^{\prime}}
$$

which is the work done by the pressure perturbation accompanying the waves plus the vertical transport of kinetic energy by the waves $\left(\left(\overline{\left.U+u^{\prime}\right)^{2} w^{\prime}} / 2 \fallingdotseq U \overline{u^{\prime} w^{\prime}}\right)\right.$. The quantity $F$ is just corresponding to our $W^{\prime * z}$, i.e.,

$$
W^{\prime * z}=W^{\prime z}+\bar{u}_{0} M^{z}
$$

(z-component of Eq. (3.24))

since $M^{z}$ is interpreted as the vertical momentum flux by planetary waves. Uryu permitted the interpretation of $F$ as the wave energy flux since the divergence of $F$ vanishes under the non-acceleration condition. However, Uryu stated that he disagreed to such an interpretation since there is a possibility of $F$ being negative in spite of the wave energy source existing below. Uryu only derived $F$ while I have constructed the consistent energy conversion equation based on the interpretation of $W^{\prime *}$ as the wave energy flux and have showed that this interpretation is related to adopting the transformed Eulerian mean equation. Anyway, the transformed energtics is useful to better understand the phenomena occurring as a result of wave mean flow interaction, although the discussion based only on the transformed energetics without referring to the ordinary energetics and the concept of the exchange of momentum between the mean flow and the waves is not productive.

In the stage of revising this paper after submission, a similar and independent work by Plumb (1983) has been published very recently. The new scheme presented by Plumb is essentially the same as that of this paper (Plumb started from the primitive equation while this paper from the quasi-geostrophic equation). The transformed eddy equation is proposed in subsection 2.2 of this paper while not in Plumb: Plump obtained the new form of the eddy energy equation by manipulating the conventional eddy energy equation. The examples to which the energetics is applied by Plumb are different from those by this paper.

\section{Acknowledgements}

I wish to thank Prof. I. Hirota of Kyoto University for his appreciation of the present work and for his comments on an earlier version of this paper, and Profs. R. Yamamoto of Kyoto University and S. Kawaguchi of National Institute of Polar Research for their encouragements. The manuscript was improved by the careful reading and constructive comments of two anonymous reviewers. Thanks are also due to Miss S. Nishikawa for typing the manuscript and Miss K. Sukeno for drafting the figures.

\section{References}

Andrews, D. G. and McIntyre, M. E., 1976: Planetary waves in horizontal and vertical shear: the generalized Eliassen-Palm relation and the mean zonal acceleration. J. Atmos. Sci., 33, 20312048.

Bretherton, F. P., 1966: Critical layer instability in baroclinic flows. Quart. J. Roy. Met. Soc., 92, $325-334$.

Charney, J. G., 1973: Planetary fluid dynamics. pp. 97-352, In Dynamic Meteorology, (Morel, P. ed.) Reidel, Dordrecht, Holland, 622 pp.

Charney, J. G. and Drazin, P. G., 1961: Propagation of planetary-scale disturbances from the lower into the upper atmosphere. J. Geophys. Res., 66, 83-110.

Charney, J. G. and Stern, M. E., 1962: On the stability of internal baroclinic jets in a rotating atmosphere. J. Atmos. Sci., 19, 159-172. 
Eady, E. T., 1949: Long waves and cyclone waves. Tellus, 1, 33-52.

Edmon, H. J., Hoskins, B. J. and McIntyre, M. E., 1980: Eliassen-Palm cross sections for the troposphere. J. Atmos. Sci., 37, 2600-2616.

Kanzawa, H., 1982: Eliassen-Palm flux diagnostics and the effect of the mean wind on planetary wave propagation for an observed sudden stratospheric warming. J. Meteor. Soc. Japan, 60, 1063-1073.

Lorenz, E. N., 1955: Available potential energy and the maintenance of the general circulation. Tellus, \%, 157-167.

Matsuno, T. and Nakamura, K., 1979: The Eulerian- and Lagrangian-mean meridional circulations in the stratosphere at the time of a sudden warming. J. Atmos. Sci., 36, 640-654.

Palmer, T. N., 1981: Diagnostic study of a wave- number-2 stratospheric sudden warming in a transformed Eulerian-mean formalism. J. Atmos. Sci., 38, 844-855.

Pedlosky, J., 1979: Geophysical Fluid Dynamics, Springer, $624 \mathrm{pp}$.

Plumb, R. A., 1983: A new look at the energy cycle. J. Atmos. Sci., 40, 1669-1688.

Sato, Y., 1980: Observational estimates of Eliassen and Palm flux due to quasi-stationary planetary waves. J. Meteor. Soc. Japan, 58, 430-435.

Uryu, M., 1974: Mean zonal flows induced by a vertically propagating Rossby wave packet. $J$. Meteor. Soc. Japan, 52, 481-490.

- 1976: Waves and wave-induced mean motions. Tenki, 23, 3-22 (in Japanese).

, 1979: Lagrangian mean motion induced by a growing baroclinic wave. J. Meteor. Soc. Japan, $\mathbf{5 \%}, \mathbf{1 - 2 0 .}$

\section{変形されたオイラー方程式に基づく準地衡風エネルギー論と 波・平均流相互作用問題への適用}

神 沢博

国立極地研究所

変形されたオイラー平均流方程式——それはエリアッセン・パルムフラックスの発散，すなわち，中高緯度の 大規模運動の場合は準地衡風らず位輸送，を陽に含む一一基づいて变形されたエネルギー変換式を導いた。波 と平均流相互作用の更なる理解のために。変形された平均エネルギー式はその良く知られた変形されたオイラー 平均流式からすぐに導ける。その変形平均流エネルギー式と辻褄の合うような変形されたじょう乱ェネルギー式 を得るために, じょう乱式を変形した。その結果, 変形されたェネルギー式を平均流とじょう乱の両方に対して 構成することができた。变形ェネルギー論においてい，平均場とじょら乱の有効位置エネルギーの間にはエネル ギーのやりとりがない。

得られたエネルギー式を 3 ツの理論モデルに適用した。すなわち, イーディの傾圧不安定, 臨界レヴェルに入 射する上方伝播定常プラネタリー波，上方伝播するプラネタリー波束の問題に。イーディ問題に括いては，傾圧 不安定にとって本質的である上下の壁の存在の重要性を変形ェネルギー論は陽に表現する。臨界レヴェル，波束 の両方の問題に対しては, 通常のエネルギー論より変形エネルギー論の方がェネルギーのやりとりの様子がより 簡単になる。エネルギー収支に正味の影響を結局はもたらさない項を変形ェネルギー式はそもそも含んでいない からである。

エネルギー論それ自身の制約はあるが，この新しい方式は，波と平均流の相互作用の起こっている状況の理解 に役立つ。 